\title{
Decreased magnesium level and membrane potential of glaucoma patients
}

\author{
Nnodim Johnkennedy*, Nsonwu Magnus**, Obioma Elemba JE**, \\ Nwadike Constance*, Edward Ukamaka*, Njoku-Obi Treasure***, \\ and Jimoh Raifu Folorunso ${ }^{\dagger}$
}

\begin{abstract}
*Department of Medical Laboratory

Science,

Faculty of Health Science,

Imo State University Owerri,

Imo State, Nigeria

**Department of Optometry,

Faculty of Health Science,

Imo State University,

Owerri,

Imo State, Nigeria

***Department of Microbiolgy,

\section{BACKGROUND}

One of the most important sight-threatening eye disorders in ophthalmology is glaucoma. Together with age related macular degeneration it is the most common cause of irreversible blindness. Magnesium ( $\mathrm{Mg}$ ) is considered to improve the ocular blood flow in glaucoma patients and could protect the retinal ganglion cell against oxidative stress. Membrane potential refers to the difference in electrical potential between the intracellular and the extracellular of a biological cell. The objective of this study was to determine the $\mathrm{Mg}$ serum level and membrane potential in glucoma subjects.
\end{abstract}

Faculty of Science,

Imo State University Owerri,

Imo State, Nigeria

Department of Medical Laboratory Services,

Federal Medical Centre,

Umuahia AbiaState, Nigeria

Correspondence:

Dr. Johnkennedy Nnodim

Department of Medical Laboratory

Science,

Faculty of Health Science,

Imo State University Owerri,

Imo State, Nigeria,

Phone: +238034237000

Email : Johnkennedy23@yahoo.com

Univ Med 2016;35:105-9

DOI: 10.18051/UnivMed.2016.v35.105-109 pISSN: 1907-3062 / eISSN: 2407-2230

This open access article is distributed under a Creative Commons Attribution-Non Commercial-Share Alike 4.0 International License

\section{METHODS}

A case-control study was conducted in eighty confirmed glaucoma patients and eighty normal subjects between 50 to 75 years were selected. The serum sodium, potassium and calcium were estimated using Randox Kit. While membrane potential was determined by calculation using Nerst Equation. Magnesium levels were determined by atomic absorption spectrophotometer technique. An independent t-test was used to analyze the data.

\section{RESULTS}

The results obtained showed that the level of Magnesium serum (1.11 \pm $0.14 \mathrm{mg} / \mathrm{dL})$ and membrane potential $(176.40 \pm 42.00 \mathrm{~J})$ was significantly decreased in glaucoma as compared to the controls $(2.4 \pm 0.68 \mathrm{mg} / \mathrm{dL})$ and $(251.76 \pm 191.99)(\mathrm{p}<0.05)$. The serum sodium, potassium and calcium were also significantly decreased among glaucoma subjects compared to control $(\mathrm{p}<0.005)$.

\section{CONCLUSION}

The result probably suggests, that decrease in magnesium aggravates glaucoma while decrease in membrane potential could cause poor energy transmission and hence affect ocular blood flow. Hence, decreased magnesium and membrane potential levels contributes greatly to glaucoma.

Keywords: Magnesium, membrane potential, glaucoma 


\section{INTRODUCTION}

Magnesium ( $\mathrm{Mg}$ ) is an abundant intracellular cation. It is considered as a cofactor in most enzymatic reactions in the body. About $50 \%$ of $\mathrm{Mg}$ is present in bones, tissues and organs while $1 \%$ in the blood stream. It is associated with many metabolic processes such as maintenance of normal cell membrane function, energy metabolism, as well as production of nucleic acids. Also, Mg tends to act as a natural physiologic calcium channel blocker. ${ }^{(1)}$ It is part of many enzymes which play essential roles in carbohydrate, protein, and fat metabolism. $\mathrm{Mg}$ is considered to improve the ocular blood flow in glaucoma patients and could protect the retinal ganglion cell against oxidative stress. ${ }^{(2)}$ It posses advantageous effects via neuronal and vascular mechanisms, which could serve as an attractive therapeutic agent in glaucoma. Additionally, Mg plays a critical role in maintaining normal nerve and muscle function, normal heart rhythm, neuromuscular conduction, muscular contraction, vasomotor tone, normal blood pressure, bone integrity, as well as glucose and insulin metabolism. ${ }^{(3)} \mathrm{Mg}$ is associated with many metabolic processes such as maintenance of normal cell membrane function, energy metabolism, and production of nucleic acids. On the other hand, patients with glaucoma could affect membrane potential. ${ }^{(4)}$ Membrane potential refers to the difference in electrical potential between the intracellular and the extracellular of a biological cell. The membrane potential result from the interaction between the membrane and the actions of two types of trans membrane proteins embedded in the plasma membrane. ${ }^{(5)}$ There is a reduction of sodium ion and potassium ion concentration gradients in glaucoma. This could be associated with increased permeability of these ions.

Glaucoma is a group of eye disorders in which the optic nerve at the back of the eye is gradually damaged. In some people this disorder could be as a result of increased pressure inside the eye or as a result of poor blood supply to the vital optic nerve fibres. It is characterized by chronic optic neuropathy leading to gradual loss of vision. ${ }^{(6)}$ Glaucoma is considered as a condition of elevated intraocular pressure (IOP), however, other risk factors may play a role in the pathogenesis of glaucomatous optic nerve damage. Vascular dysregulation in ocular blood flow and oxidative stress are important risk factors for glaucomatous retinal ganglion cell loss. In spite of the fact that anyone can get glaucoma, some people may have an increased risk, especially those with a family history of glaucoma, diabetes, migraine, short sightedness (myopia), long sightedness (hyperopia), eye injuries, blood pressure, past or present use of cortisone drugs (steroids). ${ }^{(7)}$

Also, disturbed ocular blood flow and oxidative stress could contribute to glaucoma. It is also the leading cause of blindness in Nigeria particularly in Imo State. Glaucoma is the leading cause of irreversible blindness globally and a growing public health concern because of an aging global population. If glaucoma is detected early enough, it could be possible to arrest the gradual progression with medical and surgical means. ${ }^{(8)}$

Glaucoma tends to induce oxidative stress which affects the magnesium status. ${ }^{(9)}$ Owing to scarcity of information on magnesium and membrane potential, this study tends to determine the magnesium and membrane potential among glaucoma patients aged 50 to 75 years-

\section{METHODS}

\section{Research design}

A case-control study was carried out in the Genera Hospital Owerri, Imo State Nigeria

\section{Research subjects}

Eighty patients attending General Hospital Owerri who were 50 to 75 years of age and were confirmed of glaucoma participated. Exclusions were defined as having had ocular surgery in the month prior to their appointment and/or having secondary glaucoma associated with ocular or 
systemic disorders. Subjects provided informed consent prior to enrollment in the study.

\section{Measurements}

After obtaining informed consent, subjects were provided a routine ophthalmic examination of both eyes including visual acuity assessment, intraocular pressure measurement, visual field examination, external slit lamp examination, and dilated retinal exam to confirm glaucoma.

\section{Biochemical assay}

In all subjects, $5 \mathrm{ml}$ of venous blood was collected into a non-anticoagulated tubes. The sample were spun in a Wisterfuge (model 684), centrifuge at $1000 \mathrm{~g}$ for 10 minutes and the serum collected into a clean dry bijou bottle. Magnesium and membrane potential were estimated. The serum sodium, potassium and calcium were estimated using Randox Kit. While membrane potential was determined by calculation using Nerst Equation. Magnesium levels were determined by atomic absorption spectrophotometer technique as described by Addison. ${ }^{(10)}$

\section{Statistical analysis}

The results were expressed as mean \pm standard deviation. The statistical evaluation of data was performed by using students t- test. The level of significance was calculated at $p<0.05$.

\section{Ethical clearance}

Informed consent of the participants was obtained and was conducted in line with the ethical approval of the hospital.

\section{RESULTS}

The serum sodium level in glaucoma subjects $(134.00 \pm 2.88 \mathrm{nmol} / \mathrm{L})$ was significantly lower compared to the control healthy subjects $(139.75 \pm 4.00 \mathrm{nmol} / \mathrm{L})(\mathrm{p}=0.003)$. The potassium serum level in glaucoma subjects $(3.10 \pm$ $2.88 \mathrm{nmol} / \mathrm{L}$ ) was also significantly lower than the control healthy subjects $(3.58 \pm 0.41)$ $(\mathrm{p}=0.042)$. The level of $\mathrm{Mg}$ and membrane potential, were significantly affected in glaucoma when compared with the control $(\mathrm{p}=0.047)$ (Table 1).

\section{DISCUSSION}

In this study, it was observed that Magnesium in glaucoma subjects were significantly decreased when compared with control. The is in line with the work of De Valk (11) who found that patients with severe retinopathy have a lower plasma magnesium level compared to patients without retinopathy. $\mathrm{Mg}$ tends to play an important function in insulin homeostasis. Dietary Mg intake and serum $\mathrm{Mg}$ levels were found to be inversely correlated with fasting serum insulin levels. ${ }^{(6,12)}$ Also, serum Mg concentration is known to be decreased in diabetic than in non diabetic patients. ${ }^{(13)}$ The reduction in serum magnesium was correlating with retinopathy and hypertension. ${ }^{(14)}$ It may be an added advantage in clinical practice to periodically monitor serum magnesium levels in glaucoma patients. If serum magnesium is reduced, an intervention to increase dietary intake of magnesium may be beneficial.

Table 1. Magnesium and membrane potential levels in glaucoma and control

\begin{tabular}{lccc}
\hline \multicolumn{1}{c}{ Param eters } & Control $(\mathbf{n}=\mathbf{8 0})$ & Glaucoma $(\mathbf{n}=80)$ & p \\
\hline Serum Sodium (mm ol/L) & $139.75 \pm 4.00$ & $134.00 \pm 2.88^{*}$ & 0.003 \\
Serum Potassum (m mol/L) & $3.58 \pm 0.41$ & $3.10 \pm 0.22^{*}$ & 0.042 \\
Red C ell Calcium (mm o1/L) & $0.51 \pm 0.02$ & $0.50 \pm 0.07^{*}$ & 0.049 \\
Serum C alcium (m mol/L) & $2.14 \pm 0.06$ & $1.47 \pm 0.10^{*}$ & 0.039 \\
Serum M agnesium (m g/dL) & $2.40 \pm 0.68$ & $1.11 \pm 0.14^{*}$ & 0.047 \\
Mem brane potential (J) & $251.76 \pm 19.99$ & $176.40 \pm 42.00^{*}$ & 0.019 \\
\hline
\end{tabular}

*Significantly different from control at $\mathrm{p}<0.05$ 
Glaucoma is characterized by chronic optic neuropathy leadingtogradual vision loss. Magnesium is the major intracellular divalent cation. It is usually characterized by the presence of at least two of the three hallmarks including elevated intraocular pressure, optic disc cupping, and visual field loss. ${ }^{(6)}$ The normal concentrations of extracellular Magnesium and calcium are essential for normal neuromuscular activity. Although, the intracellular magnesium forms a key complex with ATP and it is a crucial cofactor for a wide range of enzymes, transporters and nucleic acids required for normal cellular function, replication and energy metabolism. ${ }^{(11)}$

The serum Mg play an important function in the development and normal functioning of the eye. Magnesium decrease has been linked to multifocal necrosis in the retinal pigment epithelium. The low level of magnesium has been found to be correlated with pigmentaryretinal degenerations such as Kearns-Sayre syndrome and retinitis pigmentosa. ${ }^{(15,16)}$ Magnesium could be essential for maintenance of healthy ocular surface in the prevention of infections as well as dryness and in inflammatory status of conjunctiva. ${ }^{(2,17)}$ The decrease in serum and erythrocyte magnesium level is associated with advanced retinopathy. ${ }^{(18)}$ Hence, preventing low serum magnesium in glaucoma by supplementing magnesium may be beneficial. In the same vein, it was observed that the levels of serum levels sodium and potassium were significantly decreased in glaucoma when compared with healthy controls.

This results were in line with a prospective case-control study in a subpopulation of 18 patients with glaucoma, and 24 control subjects age range 30-62 years were selected from the hospital staff. This study found the serum sodium level in glaucoma subjects $(138.0 \pm 2.1 \mathrm{nmol} / \mathrm{L})$ was significantly lower compared to the control healthy subjects $(140.0 \pm 2.4 \mathrm{nmol} / \mathrm{L})(\mathrm{p}=0.006)$. And potassium serum level in glaucoma subjects $(3.7 \pm 0.3 \mathrm{nmol} / \mathrm{L})$ was also significantly lower than the control healthy subjects $(4.0 \pm 0.4)$ $(\mathrm{p}=0.002) .{ }^{(5)}$
The level of potassium ions is low in the extracellular environment while that of sodium is high. It is relevant to note that the sodium potassium ATPase and sodium potassium ion pump maintains the concentration as well as inherent electrochemical equilibrium between the extracellular and intracellular environment. This pump takes out three sodium ions for every two potassium ions taken into the cell. Therefore, this increased potassium concentration helps to draw water molecules into the cell. ${ }^{(19)}$

Our study showed that the membrane potential was significantly decreased in glaucoma patients when compared with the control. This is an agreement with the work of $\mathrm{He}$ et al. ${ }^{(20)}$ that the mitochondrial membrane potential level was decreased in glaucomatous trabecular meshwork cells.

One limitation of this study was that we did not perform a further evaluation of the exact age of glaucoma among the patients. The decrease in $\mathrm{Mg}$ and membrane potential was not correlated to period of glaucoma. Further studies on the parameters using a cohort design may be conducted to evaluate the degree of severity of glaucoma, so that the exact period of the change may be known.

\section{CONCLUSION}

It is quite obvious that the level of serum magnesium and membrane potential decreased in glaucoma.Therefore, supplementation with diets or foods rich in magnesium could be beneficial to glaucoma patients.

\section{CONFLICT OF INTEREST}

The investigators confirm that there was no conflict of interest.

\section{ACKNOWLEDGEMENT}

The investigators wish to thank the laboratory Scientists, Medical Doctors and nurses at General Hospital, Owerri Nigeria who 
assisted in this study in the collection and examination of the samples.

\section{REFERENCES}

1. Naik NS, Lamani S, Devarmani SS. The role of serum magnesium level in type 2 diabetes mellitus. Int J Res Med Sci 2015;3:556-9.

2. Wishal D, Ramdas WD, Wolfs RCW, et al. Nutrient intake and risk of open-angle glaucoma: the Rotterdam study. Eur J Epidemiol 2012; 27:385-93. DOI: 10.1007/s10654-012-9672-z.

3. Matthias B, Schulze M, Heidemann C, et al Fiber and magnesium intake and incidence of type 2 diabetes. Arch Intern Med 2007;167:956-65.

4. Mittag TW, Danias J, Pohorenec G, et al. Retinal damage after 3 to 4 months of elevated intraocular pressure in a rat glaucoma model. Invest Ophthalmol Vis Sci 2000;41:3451-9.

5. Pechere-Bertsch A, Sunaric-Megevand, Haefliger I, et al. Renal sodium handling in patients with normal pressure glaucoma. Clin Sci 2007;112:337-44. doi: 10.1042/CS200600 82.

6. Ekici F, Korkmaz F, Karaca EE, et al. The role of magnesium in the pathogenesis and treatment of glaucoma. ISRN 2014;10:1155-9.

7. Edward U, Nnodim JK, Akabogu UI, et al. Immunoglobulin expressions in glaucoma patients attending general Hospital Owerr. Res J Med Med Sci 2015;10:33-5.

8. Leffler CT, Schwartz SG, Hadi TM, et al. The early history of glaucoma: the glaucous eye (800 BC to 1050 AD). Clin Ophthalmol 2015;9:20715.

9. Chrysostomou V, Rezania F, Trounce IA, Crowston JG. Oxidative stress and mitochondrial dysfunction in glaucoma. Curr Op Pharmacol 2013;13:12-5.
10. Addison C. Clinical biochemistry: magnesium (serum, plasma). London: The Association for Clinical Biochemistry and Laboratory Medicine; 2012.

11. De Valk HW. Magnesium in diabetes mellitus. Neth J Med 1999;54:139-46.

12. Mozaffarieh M, Flammer J. New insights in the pathogenesis and treatment of normal tension glaucoma. Current Opin Pharmacol 2013;13: 43-9.

13. Mozaffarieh M, Flammer J. Is there more to glaucoma treatment than lowering Surv Ophthalmol 2007;52:174-9.

14. Smith JM, Lowe RF, Fullerton J, et al. An integrative review of the side effects related to the use of magnesium sulfate for pre-eclampsia and eclampsia management BMC Pregnancy Childbirth 2013;13:43-9.

15. Katsanos KH, Elisaf M, Bairaktari E, et al. Severe hypomagnesemia and hypoparathyroidism in Kearns-Sayre syndrome. Am J Nephrol 2001;21:150-3.

16. Mayama C. Calcium channels and their blockers in intraocular pressure and glaucoma. Eur J Pharmacol 2013;739:96-105.

17. Musso CG. Magnesium metabolism in health and disease. Int Urol Nephrol 2009;41:357-62

18. Liang SY, Lee LR. Retinitis pigmentosa associated with hypomagnesaemia. Clin Exp Ophthalmol 2010;38:645-7.

19. Bookchin RM, Etzion Z, Sorette M, et al. Identification and characterizationof newly recognized population of high $\mathrm{Na}+$, low $\mathrm{K}+$ lowdensity sickle cell and normal cells. Proc Natl Acad Sci USA 2000;97:8045-50.

20. He Y, Leung $\mathrm{KW}$, Zhang $\mathrm{YH}$, et al. Mitochondrial complex I defect induces ROS release and degeneration in trabecular meshwork cells of POAG patients: protection by antioxidants. Invest Ophthalmol Vis Sci 2008; 49:1447-58. 